\title{
Wuchereria bancrofti Filariasis Control in Samoa before PacELF (Pacific Programme to Eliminate Lymphatic Filariasis)
}

\author{
Kazuyo Ichimori $^{{ }^{*}}$, Palanitina Tupuimalagi-Toelupe ${ }^{2}$, Vailolo Toeaso Iosia ${ }^{2}$ and Patricia M. Graves ${ }^{3}$ \\ Accepted 11, September, 2007
}

\begin{abstract}
:
Background

Samoa was formerly highly endemic for Wuchereria bancrofti filariasis transmitted by Aedes mosquitoes. Previous control efforts including sporadic mass drug administration (MDA) campaigns have reduced the prevalence to low levels but have not succeeded in eliminating the disease. To effectively plan, model and evaluate the worldwide elimination effort, the Global Programme to Eliminate Lymphatic Filariasis (GPFLF) needs data on filariasis epidemiology (including age and sex-specific prevalence and the density of microfilariae (Mf)) and estimates of the number of years of MDA required for elimination. The five-year nationwide MDA campaign carried out in Samoa before the start of the Pacific Programme to Eliminate Lymphatic Filariasis (PacELF) generated extensive data on these issues.

Methodology/Principal Findings

MDA campaigns were conducted in Samoa with diethylcarbamazine (DEC) in 1993 to 1995 and DEC plus ivermectin in 1996 to 1997 for all persons aged 2 years and above. Coverage of the MDA, as assessed from the campaign village register books, ranged from $62 \%$ to $97 \%$ depending on the year, and was over $80 \%$ in three out of five years. Village based surveys showed that prevalence of Mf declined from $4.3 \%$ in $1993(\mathrm{~N}=10,256)$ to $1.1 \%$ in $1998(\mathrm{~N}=4,054)\left(\mathrm{P} \chi^{2}=94.4, \mathrm{p}<0.001\right)$. Males had a three- to five-fold higher prevalence than females, and this difference remained consistent over the five-year period. Transmission was still occurring over the period as shown by the occurrence of new infections in 3 children less than 5 years old out of 5,691 tested (five-year cumulative incidence of 0.53 per thousand children for the period 1993 to 1998). There was a statistically significant reduction in the geometric mean number of Mf per $60 \mu \mathrm{l}$ in positive cases between $1993(11.8)$ and $1998(6.9)(\mathrm{t}=2.61 ; \mathrm{p}<0.01)$. The proportion of people with a high density of Mf - over $60 \mathrm{Mf}$ per $60 \mu \mathrm{l}$ (1000 per ml) - declined from to $19.4 \%$ to $4.0 \%\left(\mathrm{P} \chi^{2}=5.6, \mathrm{p}=0.018\right)$.

Conclusions/Significance

Five years of sustained MDA with DEC (3 years) and DEC plus ivermectin (2 years) reduced the prevalence of Mf of W.bancrofti in Samoa by 74\%. Density of Mf in infected individuals was also significantly reduced. Males had a three to five-fold higher prevalence than women. New infections in children less than five years old still occurred at a low level, suggesting that transmission was not completely interrupted. These findings helped to prepare a sound monitoring and evaluation plan for PacELF.
\end{abstract}

Key words: Samoa; diethylcarbamazine; Global Programme to Eliminate Lymphatic Filariasis; mass drug administration; PacELF

\section{INTRODUCTION}

Filariasis in Samoa and its past control activities

Samoa is a nation consisting of two main islands (Upolu and Savaii), two small inhabited islands Apolima (A) and Monono-Tai (M-T), and five uninhabited islands (Figure 1), covering a land area of 2,935 sq $\mathrm{km}$ located at approxi- mately latitude $14^{\circ} \mathrm{S}$ and longitude $172^{\circ} \mathrm{W}$ in the Pacific Ocean. The population of Samoa (formerly known as Western Samoa) was estimated at 161,298 in the 1991 census and 174,140 in the 2001 census [1].

Filariasis in Samoa is caused by Wuchereria bancrofti of the diurnally subperiodic type [2], which means that Mf are

\footnotetext{
${ }^{1}$ Department of Control of Neglected Tropical Diseases, World Health Organization, Avenue Appia 20, 1211 Geneva 27, Switzerland. Tel 412279127 67, Fax 412279148 69, ichimorik@who.int

${ }^{2}$ Ministry of Health, Samoa, Private Mail Bag Motootua Apia, Samoa. Tel 685 21212, Fax 685 26553, ceo@ health.gov.ws

${ }^{3}$ EpiVec Consulting, Atlanta GA 30306, USA. Tel 404293 3529. Fax 7704884521 epivec@ comcast.net

* Corresponding author

E-mail address: ichimorik@who.int
} 
Figure 1: Map of Samoa showing population category by health district, 1991

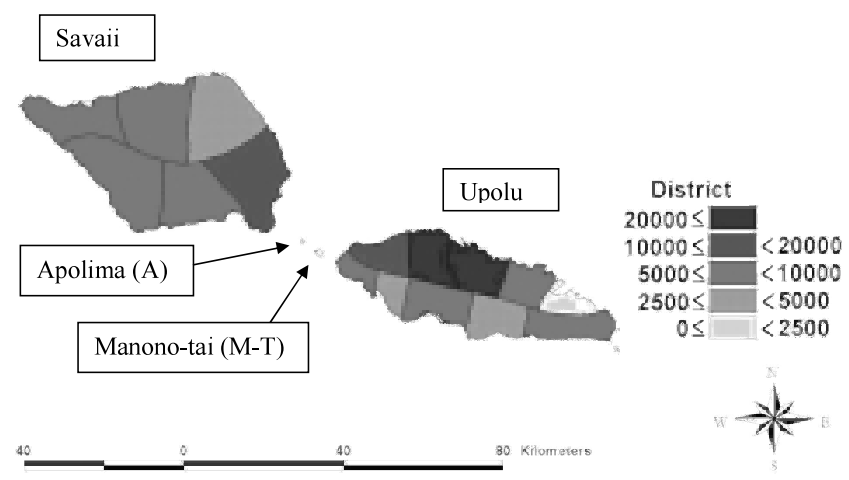

Figure 2:Mf prevalence and mass drug administration campaigns in Samoa, 1923 to 1998

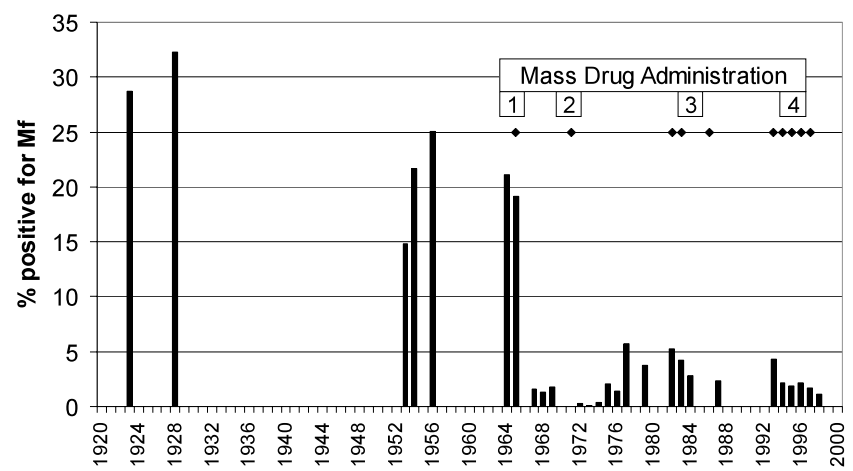

1: DEC $5 \mathrm{mg} / \mathrm{kg}$ once a week for a month then once a month for 18 months

2: DEC $6 \mathrm{mg} / \mathrm{kg}$ once a month for 12 months

3: DEC $6 \mathrm{mg} / \mathrm{kg}$ single dose once a year

4: Current study: DEC $6 \mathrm{mg} / \mathrm{kg}$ single dose once a year (1993, 1994, 1995); DEC $6 \mathrm{mg} / \mathrm{kg}$ plus ivermectin $200 \mu \mathrm{g} / \mathrm{kg}$ single dose once a year $(1996,1997)$.

Sources:

1923: O'Connor [7]

1928: Buxton and Hopkins [8], Buxton [9]

1953, 1954, 1956, 1964, 1965, 1967--1969, 1972-1977: Country

data (Ministry of Health)

1979: Kimura et al [11]

1982-1984, 1987: Kimura et al [12]

1993--1998: current study

found in the peripheral blood in greater numbers during the daytime hours. The two known mosquito vectors of filariasis in Samoa are Aedes (Stegomyia) polynesiensis and Aedes (Ochlerotatus) samoanus, (formerly Aedes (Finlaya) samoanus), which bite predominantly by day and night respectively (reviewed in [3]). The relative distribution of the vector species is correlated with the predominance of potential breeding sites, including crab holes, domestic containers and leaf axils of Pandanus spp. Of the two vectors, Ae. polynesienesis is regarded as the dominant one [4].

Samoa's high level of infection with lymphatic filariasis, and consequent high number of people with elephantiasis, has been known since the 1920s. In his review of human filariasis [5], Sasa cites O'Connor [6] who found that 29\% of people in Samoa (Western and American combined) were infected, and Buxton [7,8] who demonstrated an Mf prevalence of $24 \%$ in Upolu and $41 \%$ in Savaii. At this time $6 \%$ of the male population was estimated to have elephantiasis. By the late 1950s, the prevalence of Mf in Samoa was still around 20\% [9] (Figure 2).

The history of filariasis control in Samoa has been reviewed by Ichimori [3]. The history of MDA campaigns and prevalence survey estimates are shown in Figure 2. The MDA began in Samoa in 1965, when the prevalence of Mf was $19 \%$. DEC at $5 \mathrm{mg} / \mathrm{kg}$ was given once weekly for 6 weeks, followed by once a month for 12 months [10]. The coverage was $95 \%$ for the first dose, but only $20 \%$ of the population took all18doses. The Mf rate after this MDA was 1.6\% [10]. A further MDA in 1971 with DEC $6 \mathrm{mg} / \mathrm{kg}$ given monthly for 12 months reduced the Mf rate to a reported $0.2 \%$ in 1972; this time the MDA coverage was $99 \%$ for the first dose and $46 \%$ for all 12 doses [11]. Ten years later, the Mf rate had risen again to $5.3 \%$ [12]. Then DEC at $6 \mathrm{mg} / \mathrm{kg}$ was offered annually in 1982, 1983, and 1986, after which the Mf prevalence was estimated to be $2.3 \%$ in 1987 [11].

Infective rates in mosquitoes (proportion of mosquitoes with the $3^{\text {rd }}$ larval stage) were $3 \%$ in 1963 but had dropped to $0.4 \%$ after the first MDA in 1965 [12]. No significant further decline in infective rate was observed in the 1970s [4] but by 1984, only one infective mosquito was found out of over 5,000 dissected giving an estimate of $0.02 \%$ infective mosquitoes [10]. It is known that Ae. polynesiensis can become infected from extremely low densities of Mf, and may be able to "concentrate" the worms during feeding [13]. Although low-density carriers may have been of limited significance when they were a low proportion of the population [14], filariasis control based on drug treatment is likely to markedly increase the proportion of low-density infections. The importance of these low-density infections in transmission and the potential for elimination needs further study.

\section{Background and purpose of this study}

Although five MDAs were conducted in Samoa between 1965 and 1987 with reportedly good coverage of the population, they were each done for only one year or at most two consecutive years. The fact that DEC does not kill all the 
adult worms, which live for several years, may have made it possible for the Mf prevalence rate to rebound in the intervening and subsequent years. Therefore a series of five consecutive annual MDAs with DEC (3 years) or DEC plus ivermectin (2 years) were carried out from 1993 to 1997. GPELF is currently working to eliminate filariasis as a public health problem by the year 2020 [15]. The primary strategy is MDA to populations at risk for a number of consecutive years (estimated at 4-6). The number of years of MDA required to completely eliminate transmission is not known. It is also not known at what level of Mf or filarial antigen prevalence it is safe to assume that the disease will not resurge and therefore that MDA can be stopped.

In the Pacific region, which had some of the highest prevalence rates and some of the most efficient mosquito vectors in the world, large scale filariasis control programs have been underway in countries such as Samoa and French Polynesia for many years prior to the start of GPELF in the late 1990s and early 2000s. Experience gained in these prior campaigns is useful for countries currently attempting MDA programmes for the first time.

This paper describes the effect of a five-year MDA programme in Samoa during the period from 1993 to 1997 , with a further survey in 1998. The drugs used in these campaigns were DEC (for 3 years) and DEC plus ivermectin (for 2 years). The current strategy for the GPELF is to use DEC plus albendazole in MDA. However, there is insufficient evidence that this combination is superior to DEC alone [16]. Therefore we believe the results given here are relevant to the GPELF activities. The implementation and monitoring of this campaign is described in this paper.

PacELF commenced in 1999 [17], and Samoa was the first country to initiate annual MDA in that year with DEC and albendazole, as recommended by GPELF. [18, 19].

\section{METHODS}

\section{Implementation of the MDA}

Samoa has 16 health districts representing administrative units for the health system. These districts are shown in Figure 1 together with population density estimates from the 1991 census. MDA was organized within the health districts and implemented by nurses with the help of the village Women's committees which are an important part of the social structure in Samoa (the Matai or chief system). Women's committees and district nurses did a census of each village in 1993 before the MDA to predict the required amount of drugs and other supplies needed, as well as to be able to estimate treatment coverage after the MDA. Registration books listing every family and its members by name were prepared before the MDA.

DEC at 6mg/kg was given in 1993, 1994 and 1995 while DEC plus ivermectin $(200 \mu \mathrm{g} / \mathrm{kg})$ were given in 1996 and 1997. The policy was that treatment be taken immediately and directly observed. The following persons were excluded from MDA: children before the second birthday, pregnant women, and very sick individuals. The doses of DEC 50mg tablets were estimated by age categories as follows:

Age 2-4 years: 2 tablets; age 5-9 years: 3 tablets; age 10-14 years: 5 tablets; age 15-19 years: 7 tablets; age 20-49 years: 9 tablets; age50or more years: 8 tablets.

Coverage in the MDA (proportion of the population who received the tablets) was calculated using the population estimates in the registration books.

\section{Blood surveys for prevalence of $M f$}

Nationwide prevalence surveys were conducted annually in 1993 and 1997, before and between the MDA campaigns, and also in 1998, one year after the last MDA. All surveys were done in the daytime by blood slide survey for Mf, except in 1998 when both blood slides and immunochromatographic (ICT) tests for filarial antigen were done.

All inhabitants of selected villages were requested to appear at a central location in the village between the hours of 9 am and $5 \mathrm{pm}$. After completing demographic information, fingerprick blood samples of $60 \mu \mathrm{l}$ were taken and streaked in three lines of approximately $20 \mu \mathrm{l}$ each on a glass slide. After thorough drying, the slides were dehaemoglobinised in water and stained with Giemsa. All three lines were examined under 40x power and the total number of Mf on the slide (i.e. per $60 \mu \mathrm{l}$ ) counted.

Surveys for Mf prevalence and density were done in a purposive or convenience sample of villages selected to represent health districts, with up to 9 villages per health district being selected. The villages differed each year. Because the probability of selection of each village in a district is not known, it has not been possible to fully adjust the survey results. However, district-adjusted results are presented for 1993 and 1998 assuming that all villages in a district had equal probability of selection.

Treatment and follow-up of positive cases

Any persons found to be positive for Mf at surveys were treated at follow-up visits using a dose of $6 \mathrm{mg} / \mathrm{kg}$ of DEC given for 12 days. They were followed up by a repeat visit 
6 months later to ensure that they were negative for Mf.

\section{Statistical analysis}

Chi-squared tests and t-tests were performed using Epi-Info for Windows or STATA version 7, which was also used to determine $95 \%$ confidence intervals for proportions.

\section{RESULTS}

\section{Sampling population}

The proportion of the total population of Samoa tested each year for Mf was quite large, ranging from $2.8 \%$ in 1995 to $6.2 \%$ in 1993. There was however potential for bias in the samples due to the unequal sampling probability by district. Therefore the results for 1993 and 1997 were adjusted for the district sampling fraction, assuming all villages within a district had equal probability of being selected. This adjustment could not be done for 1998 because district specific data were not available. The district population sizes were increased by $0.65 \%$ per year, which is the average of the growth rates for 1991 and 1996 from the Samoa Department of Statistics [2]. The adjusted prevalence (shown in Table 1) was higher (4.5\%) in 1993 than the unadjusted estimate $(4.3 \%)$, but the two estimates were similar in 1997 ( $1.7 \%$ in both cases). Therefore, we believe it is justifiable to use the unadjusted rates since if anything, they tend to underestimate the fall in prevalence.

\section{MDA coverage}

The reported coverage with MDA (percent of registered

Table 1 Prevalence and Mf density by gender and year, Samoa, 1993-1998.

\begin{tabular}{|l|r|r|r|r|r|r|}
\hline & 1993 & \multicolumn{1}{|c|}{1994} & \multicolumn{1}{|c|}{1995} & \multicolumn{1}{c|}{1996} & 1997 & \multicolumn{1}{|c|}{1998} \\
\hline $\begin{array}{l}\text { Estimated } \\
\text { population }\end{array}$ & 162915 & 163729 & 164548 & 165371 & 166694 & 168027 \\
\hline & & & & & & \\
\hline No. examined & 10256 & 10112 & 4551 & 5997 & 8305 & 4054 \\
\hline No. positive & 444 & 225 & 86 & 133 & 141 & 43 \\
\hline & & & & & & \\
\hline Mf rate, \% Male & 6.6 & 3.4 & 3.3 & 3.2 & 3.0 & 1.7 \\
\hline Female & 2.2 & 1.1 & 0.6 & 1.3 & 0.5 & 0.4 \\
\hline Total & 4.3 & 2.2 & 1.9 & 2.2 & 1.7 & 1.1 \\
\hline & & & & & & \\
\hline Mdjusted Mf rate & 4.5 & & & & 1.7 & \\
\hline $\begin{array}{l}\text { Mf density } \\
\text { (geom. mean): }\end{array}$ & & & & & & \\
\hline Male & 13.5 & 12.1 & 6.6 & 12.6 & 9.1 & - \\
\hline Female & 8.0 & 10.5 & 8.2 & 9.4 & 8.1 & - \\
\hline Total & 11.8 & 11.7 & 6.8 & 11.5 & 8.9 & 6.9 \\
\hline & & & & & & \\
\hline
\end{tabular}

* projected from 1991 census population by Department of Statistics, Samoa
Figure 3: Reported MDA coverage by year, 1993 to 1997 and Mf prevalence, 1993 to 1998

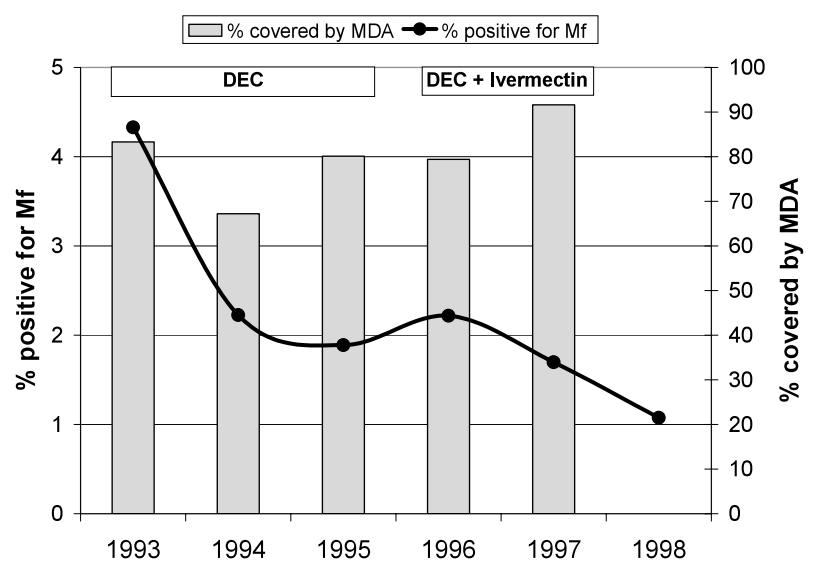

population subjected to MDA) each year is shown in Figure 3. Coverage ranged from $67 \%$ in 1994 to $92 \%$ in 1997 and reached the target of $80 \%$ in only three out of the five years. Coverage by age or sex was not available.

\section{Overall prevalence}

In 1993, the overall prevalence of Mf in Samoa was $4.3 \%$ ( $95 \%$ confidence interval (CI): $3.9 \%$ to $4.7 \%$ ) out of 10,256 people tested in 32 villages (Table 2). The highest prevalence $(7.5 \%$, CI: $5.9 \%$ to $9.4 \%$ ) was in district 2 , but it was also high on the two small islands of Monono-Tai and Apolima (7.3\%, CI: $5.5 \%$ to $9.4 \%$ ). On the rest of Upolu island (excluding the two small islands) it was $4.5 \%$. Upolu had a higher prevalence rate than Savaii in 1993: 4.8\% versus $3.7 \%$ respectively, $\left(\mathrm{P} \chi^{2} 8.31, \mathrm{p}=0.004\right)$. All16health districts had some filariasis infection; district 5 was lowest with $1.3 \%(0.3 \%$ to $3.2 \%)$ positive.

By 1997, after four rounds of MDA, the prevalence of infection was reduced in the country as a whole from $4.3 \%$ (95\%, CI: $3.9 \%$ to $4.7 \%$ ) to $1.7 \%$ (1.5\% to $2.0 \%$ ). (Table 2 ). A follow up survey in 1998 (one year after last MDA) showed a further decline to $1.1 \%(0.8 \%$ to $1.4 \%)$. The decline from 1993 to 1998 was highly significant $\left(\mathrm{Px}^{2}=94.4, \mathrm{p}\right.$ $<0.001)$.

In 1998 the survey tested participants using both slides and the ICT test. The antigenemia prevalence by ICT was $4.2 \%$ $(\mathrm{N}=4,054)$. Thus ICT tests gave an estimate 3.8 fold higher than the Mf prevalence by blood slide.

\section{Density and frequency distribution of $M f$}

Figure 4 shows the location of all the villages in which blood surveys were done from 1993 to 1997. Most tested villages on Savaii had a prevalence lower than $5 \%$ (green or 
Table 2: Prevalence of microfilaria in Samoa by health district, main island, and total, 1993-1997

\begin{tabular}{|c|c|c|c|c|c|c|c|c|c|c|c|c|c|c|c|c|c|c|c|c|c|c|}
\hline \multirow[t]{2}{*}{ Is land } & \multirow{2}{*}{$\begin{array}{l}\text { Health } \\
\text { district }\end{array}$} & \multirow{2}{*}{$\begin{array}{l}\text { Population } \\
1991\end{array}$} & \multicolumn{4}{|c|}{1993} & \multicolumn{4}{|c|}{1994} & \multicolumn{4}{|c|}{1995} & \multicolumn{4}{|c|}{1996} & \multicolumn{4}{|c|}{1997} \\
\hline & & & $\begin{array}{c}\text { No } \\
\text { vills } \\
\end{array}$ & $\begin{array}{c}\text { No } \\
\text { tested }\end{array}$ & $\begin{array}{l}\text { No } \\
\text { pos }\end{array}$ & $\begin{array}{c}\% \\
\text { pos }\end{array}$ & $\begin{array}{l}\text { No } \\
\text { vills }\end{array}$ & $\begin{array}{c}\text { No } \\
\text { tested }\end{array}$ & \begin{tabular}{|l|} 
No \\
pos
\end{tabular} & $\begin{array}{c}\% \\
\text { pos }\end{array}$ & $\begin{array}{l}\text { No } \\
\text { vills }\end{array}$ & \begin{tabular}{|c|} 
No \\
tested
\end{tabular} & \begin{tabular}{|l|} 
No \\
pos
\end{tabular} & $\begin{array}{c}\% \\
\text { pos }\end{array}$ & $\begin{array}{l}\text { No } \\
\text { vills }\end{array}$ & $\begin{array}{c}\text { No } \\
\text { tested }\end{array}$ & \begin{tabular}{|l|} 
No \\
pos
\end{tabular} & $\begin{array}{c}\% \\
\text { pos }\end{array}$ & $\begin{array}{l}\text { No } \\
\text { vills } \\
\end{array}$ & \begin{tabular}{|c|} 
No \\
tested
\end{tabular} & $\begin{array}{l}\text { No } \\
\text { pos }\end{array}$ & $\begin{array}{c}\% \\
\text { pos }\end{array}$ \\
\hline \multirow[t]{10}{*}{ Up olu } & 0 & 33931 & 5 & 1456 & 37 & 2.5 & 3 & 1001 & 9 & 0.9 & 3 & 617 & 3 & 0.5 & 9 & 1271 & 27 & 2.1 & 9 & 2521 & 19 & 0.8 \\
\hline & 1 & 28875 & 2 & 496 & 36 & 7.3 & 3 & 586 & 9 & 1.5 & 3 & 356 & 25 & 7.0 & 5 & 699 & 19 & 2.7 & 3 & 1332 & 22 & 1.7 \\
\hline & 2 & 13053 & 3 & 959 & 72 & 7.5 & 1 & 586 & 17 & 2.9 & 3 & 492 & 11 & 2.2 & 2 & 525 & 25 & 4.8 & 2 & 547 & 23 & 4.2 \\
\hline & $3^{*}$ & 7312 & 0 & & & & 1 & 337 & 5 & 1.5 & 1 & 293 & 1 & 0.3 & 1 & 140 & 2 & 1.4 & 1 & 270 & 17 & 6.3 \\
\hline & 4 & 4044 & 0 & & & & 1 & 297 & 3 & 1.0 & 0 & & & & 1 & 44 & 0 & 0.0 & 1 & 223 & 1 & 0.4 \\
\hline & 5 & 8141 & 1 & 315 & 4 & 1.3 & 3 & 1087 & 17 & 1.6 & 1 & 155 & 1 & 0.6 & 1 & 386 & 1 & 0.3 & 1 & 155 & 1 & 0.6 \\
\hline & 6 & 4781 & 2 & 527 & 13 & 2.5 & 1 & 440 & 7 & 1.6 & 1 & 148 & 6 & 4.1 & 2 & 277 & 5 & 1.8 & 2 & 401 & 2 & 0.5 \\
\hline & 7 & 7126 & 2 & 679 & 27 & 4.0 & 3 & 807 & 42 & 5.2 & 2 & 480 & 9 & 1.9 & 2 & 533 & 22 & 4.1 & 1 & 95 & 2 & 2.1 \\
\hline & 8 & 1400 & 1 & 72 & 3 & 4.2 & 1 & 112 & 0 & 0.0 & 0 & & & & 1 & 69 & 0 & 0.0 & 1 & 65 & 0 & 0.0 \\
\hline & 9 & 6967 & 2 & 643 & 39 & 6.1 & 2 & 380 & 4 & 1.1 & 2 & 363 & 3 & 0.8 & 0 & & & & 1 & 96 & 0 & 0.0 \\
\hline & & & & & & & & & & & & & & & & & & & & & & \\
\hline Monono-Tai & $3^{*}$ & & 1 & 685 & 49 & 7.2 & 0 & & & & 0 & & & & 0 & & & & 0 & & & \\
\hline Apolima & $3^{*}$ & & 1 & 46 & 4 & 8.7 & 0 & & & & 0 & & & & 0 & & & & 0 & & & \\
\hline \multirow[t]{7}{*}{ Savaii } & 10 & 13342 & 2 & 622 & 26 & 4.2 & 3 & 1069 & 27 & 2.5 & 2 & 285 & 6 & 2.1 & 2 & 665 & 15 & 2.3 & 2 & 430 & 4 & 0.9 \\
\hline & 11 & 3986 & 1 & 444 & 10 & 2.3 & 1 & 160 & 7 & 4.4 & 1 & 215 & 2 & 0.9 & 1 & 222 & 0 & 0.0 & 1 & 146 & 0 & 0.0 \\
\hline & 12 & 5262 & 2 & 438 & 10 & 2.3 & 1 & 241 & 10 & 4.1 & 1 & 163 & 2 & 1.2 & 1 & 305 & 6 & 2.0 & 1 & 423 & 14 & 3.3 \\
\hline & 13 & 7476 & 3 & 896 & 36 & 4.0 & 2 & 958 & 27 & 2.8 & 1 & 409 & 5 & 1.2 & 1 & 394 & 5 & 1.3 & 1 & 983 & 19 & 1.9 \\
\hline & 14 & 7442 & 3 & 1222 & 48 & 3.9 & 2 & 782 & 30 & 3.8 & 1 & 411 & 7 & 1.7 & 1 & 195 & 5 & 2.6 & 1 & 395 & 12 & 3.0 \\
\hline & 15 & 7315 & 1 & 756 & 30 & 4.0 & 2 & 1269 & 11 & 0.9 & 1 & 164 & 5 & 3.0 & 1 & 272 & 1 & 0.4 & 1 & 223 & 5 & 2.2 \\
\hline & & & & & & & & & & & & & & & & & & & & & & \\
\hline Total Upolu & & & 18 & 5147 & 231 & 4.5 & 19 & 5633 & 113 & 2.0 & 16 & 2904 & 59 & 2.0 & 24 & 3944 & 101 & 2.6 & 22 & 5705 & 87 & 1.5 \\
\hline Total M-T \& A & & & 2 & 731 & 53 & 7.3 & 0 & & & & 0 & & & & 0 & & & & 0 & & & \\
\hline Total U, M-T, A & & & 20 & 5878 & 284 & 4.8 & 19 & 5633 & 113 & 2.0 & 16 & 2904 & 59 & 2.0 & 24 & 3944 & 101 & 2.6 & 22 & 5705 & 87 & 1.5 \\
\hline Total Savaii & & & 12 & 4378 & 160 & 3.7 & 11 & 4479 & 112 & 2.5 & 7 & 1647 & 27 & 1.6 & 7 & 2053 & 32 & 1.6 & 7 & 2600 & 54 & 2.1 \\
\hline TOTAL & & 161298 & 32 & 10256 & 444 & 4.3 & 30 & 10112 & 225 & 2.2 & 23 & 4551 & 86 & 1.9 & 31 & 5997 & 133 & 2.2 & 29 & 8305 & 141 & 1.7 \\
\hline
\end{tabular}

"the 2s mall is lands Monono-Taiand Apolima are part of health district3on Upolu, but are reported separately

Figure 4: Prevalence of Mf by village,1993-1997

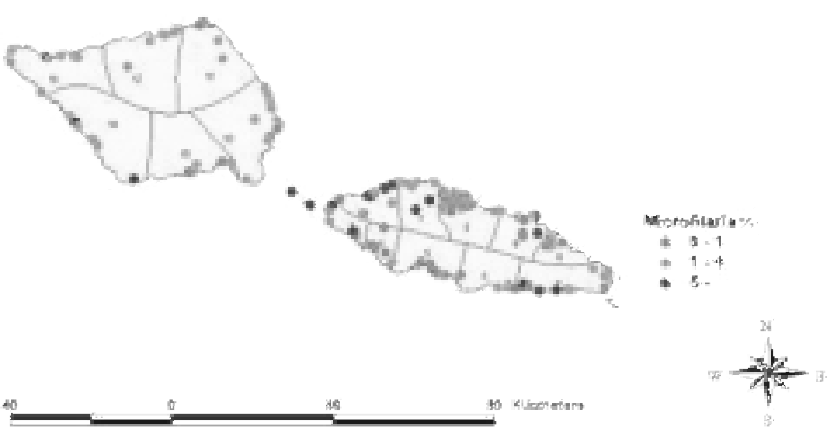

yellow dots), whereas Upolu showed more variation. There was a concentration of high prevalence villages $(>5 \%$, red) on the north and west of Upolu island.

Reduction in prevalence was observed in all health districts except number 12 (Table 2). In 1997, no infections were detected in 3 health districts, and in the others prevalence ranged from 0.4 to $6.3 \%$ positive. In 1997, the highest prevalence of $6.3 \%$ was observed in health district 3, which includes the small islands of Monono-Tai and Apolima. However, the surveys in 1997 were done on the main island
Figure 5: Samoa Mf prevalence in the main islands of Upolu and Savaii, 1993-1998

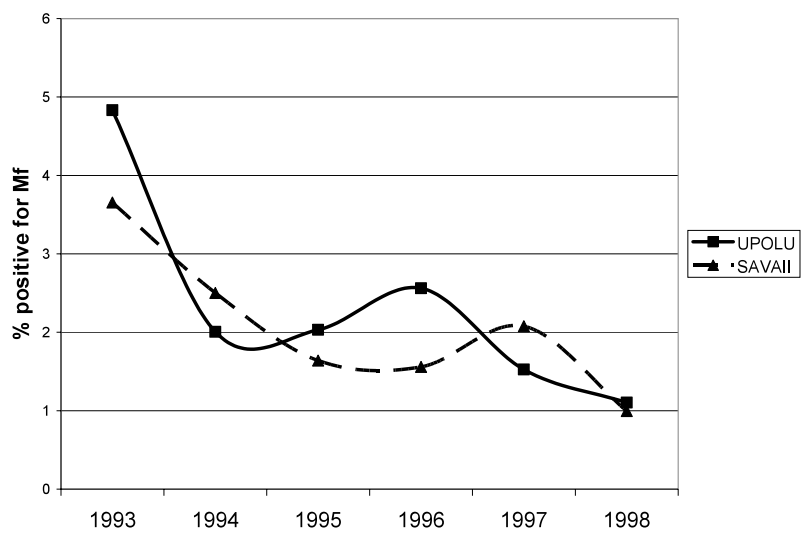

part of district 3 .

Overall the prevalence on Upolu in 1997 was $1.5 \%$ (1.2\% to $1.9 \%$ ) and on Savaii $2.1 \%$ (1.6\% to $2.7 \%)$. The difference in prevalence between the two large islands seen in 1993 (4.8 vs 3.7 as mentioned above) was no longer statistically significant $\left(\mathrm{P} \chi^{2}=3.26, \mathrm{p}=0.07\right)$. Similar patterns of decline followed by increase and then further decline were seen in 
Table 3: Geometric mean Mf density and number of positive cases by district, island and year, 1993-1998.

\begin{tabular}{|c|c|c|c|c|c|c|c|}
\hline & & & Geometric & mean $\mathrm{Mf}_{\mathrm{f}}$ & er $60 \mathrm{ul} \mathrm{(no}$ & positive) & \\
\hline Island & District & 1993 & 1994 & 1995 & 1996 & 1997 & 1998 \\
\hline Upolu & 0 & $17.2(37)$ & 7.9 (9) & 6.2 (3) & $10.1(27)$ & $6.2(19)$ & $7.3(9)$ \\
\hline & 1 & $18.1(36)$ & $16.8(9)$ & $6.6(25)$ & $7.4(19)$ & $7.3(22)$ & $8.1(12)$ \\
\hline & 2 & $11.9(41)$ & $9.3(17)$ & $5.4(11)$ & $7.9(25)$ & $15.6(23)$ & \\
\hline & 3 & $9.8(84)$ & $11.6 \quad(5)$ & 52 (1) & $19.9 \quad(2)$ & $8.6(17)$ & \\
\hline & 4 & & $25.0 \quad(3)$ & & & 64 (1) & \\
\hline & 5 & $20.4 \quad(4)$ & $10.2(17)$ & 1 (1) & $\begin{array}{ll}4 & (1) \\
\end{array}$ & $163 \quad(1)$ & \\
\hline & 6 & $8.9(13)$ & $\begin{array}{ll}7.0 & \text { (7) }\end{array}$ & $6.3(6)$ & $18.9 \quad(5)$ & 8.7 (2) & \\
\hline & 7 & $17.1(27)$ & $16.2(42)$ & $5.5 \quad(9)$ & $17.9(22)$ & $10.8 \quad(2)$ & $15.0 \quad(3)$ \\
\hline & 8 & $2.9 \quad(3)$ & & & & & 1.8 (3) \\
\hline & 9 & $15.5(39)$ & $10.5 \quad(4)$ & 3.6 (3) & & & $4.4 \quad(5)$ \\
\hline Savaii & 10 & $8.5(26)$ & $8.6(27)$ & 25.2 (6) & $17.4(15)$ & 12.0 & $5.8 \quad(3)$ \\
\hline & 11 & $10.0(10)$ & $16.0 \quad(7)$ & $5.3(2)$ & & & $28 \quad(1)$ \\
\hline & 12 & $13.0(10)$ & $18.5(10)$ & $8.6 \quad(2)$ & $25.6 \quad(6)$ & $10.9(14)$ & $1 \quad(1)$ \\
\hline & 13 & $12.4(36)$ & $12.9(27)$ & $5.0 \quad(5)$ & $\begin{array}{ll}9.9 & (5)\end{array}$ & $5.7(19)$ & \\
\hline & 14 & $10.1(48)$ & $9.2(30)$ & $\begin{array}{ll}7.8 \quad(7) \\
\end{array}$ & $9.1 \quad(5)$ & $8.5(12)$ & $4.3 \quad(6)$ \\
\hline & 15 & $7.9(30)$ & $12.1(11)$ & $7.0 \quad(5)$ & $12 \quad(1)$ & $8.0 \quad(5)$ & $12.2(9)$ \\
\hline Over & GM & $\begin{array}{r}11.8 \\
(444)\end{array}$ & $\begin{array}{r}11.7 \\
(225)\end{array}$ & $\begin{array}{r}6.8 \\
(86)\end{array}$ & $\begin{array}{r}11.5 \\
(133)\end{array}$ & $\begin{array}{r}8.9 \\
(141)\end{array}$ & $\begin{array}{r}6.9 \\
(43)\end{array}$ \\
\hline
\end{tabular}

both main islands (Figure 5) although there was no significant difference.

Table 3 shows the mean density of Mf in positive cases per $60 \mu \mathrm{l}$ by district and year. Overall the geometric mean of Mf declined significantly from 11.8 (95\% CI 10.4 to 13.8 ) in 1993 to 6.9 (4.8 to 9.9) in 1998 ( $\mathrm{t}=2.6075, \mathrm{p}<0.01)$. These counts represent 197 and $115 \mathrm{Mf}$ per ml respectively.

\section{Age- and sex-specific prevalence}

The prevalence of Mf was much higher (3- to 5- fold) in males than females, and this difference remained constant over the five-year period (Table 1). For example, in 1993 males had 6.6\% prevalence and females $2.2 \%\left(\mathrm{P} \chi^{2}=120.0 ; \mathrm{p}\right.$ $<0.0001)$; in 1998 males had $1.7 \%$ and females $0.4 \%\left(\mathrm{P} \chi^{2}=\right.$ 16.7, $\mathrm{p}<0.0001)$. The density of Mf, on the other hand, was only slightly higher in males than females (Table 1).

Infection rates in children under 10 years of age were investigated to determine whether there were new cases reflecting ongoing transmission. The infection rate in 5-9 year olds was higher than in 0-4 year olds (Table 4). Thirty infected children were detected in the 5-9 year age group out of 8103 tested $(0.37 \%)$. Three children under five were found positive for Mf out of 5671 tested, two in 1994 and one in $1998(0.053 \%)\left(\mathrm{P} \chi^{2}=12.76 ; \mathrm{p}<0.001\right)$. There was no statistically significant decline between1993and1998in the number of children under ten who were infected $\left(\chi^{2}=1.07, \mathrm{p}\right.$ $=0.302$ ) but numbers in this age group were small.
Table 4: Children under ten years of age found positive in blood surveys, 1993-1998

\begin{tabular}{|l|l|l|l|l|}
\hline Year & \multicolumn{1}{c|}{ Age-group } & \multicolumn{1}{c|}{$0-4$} & \multicolumn{1}{c|}{$5-9$} & \multicolumn{1}{c|}{ Total } \\
\hline 1993 & Positive & 0 & 13 & 13 \\
\hline & No. tested & 1220 & 1814 & 3034 \\
\hline 1994 & Positive & 2 & 7 & 9 \\
\hline & No. tested & 1330 & 1746 & 3076 \\
\hline 1995 & Positive & 0 & 2 & 2 \\
\hline & No. tested & 617 & 900 & 1517 \\
\hline 1996 & Positive & 0 & 2 & 2 \\
\hline & No. tested & 822 & 1128 & 2000 \\
\hline 1997 & Positive & 0 & 4 & 4 \\
\hline & No. tested & 1089 & 1539 & 2628 \\
\hline 1998 & Positive & 1 & 2 & 3 \\
\hline & No. tested & 593 & 976 & 1569 \\
\hline & & & & \\
\hline & Total positive & 3 & 30 & 33 \\
\hline & Total tested & 5671 & 8103 & 13774 \\
\hline & 5 yr incidence/1000 & 0.53 & 3.70 & 2.40 \\
\hline
\end{tabular}

Since we can assume that all the 0-5 year-olds were negative at birth, the number of cases in this age group suggests that the five-year cumulative incidence was 0.53 per thousand children for the period 1993 to 1998. A more conservative approach assumes only that the 593 children tested in 1998 (those born since the start of MDA in 1993) were initially uninfected. This yields an estimate of 1.7/1000 new infections per 5 years of exposure.

We examined the pattern of age-specific prevalence of Mf by age group and sex (Figures 6 to 8 ). Note the different scales on the graphs for male and female prevalence. We include data from 1982 and 1983 from Kimura et al [11,12] in these figures for comparison. Figure 6 shows that in males, the age-specific prevalence curve was essentially the same in 1993 as it had been in 1982 and 1983, showing a pattern of gradually increasing positivity with age. After the first MDA of the current series in 1993, there was a large

Figure 6. Age-specific prevalence of Mf in Samoa, MALES, 1982, 1983 and 1993--1998

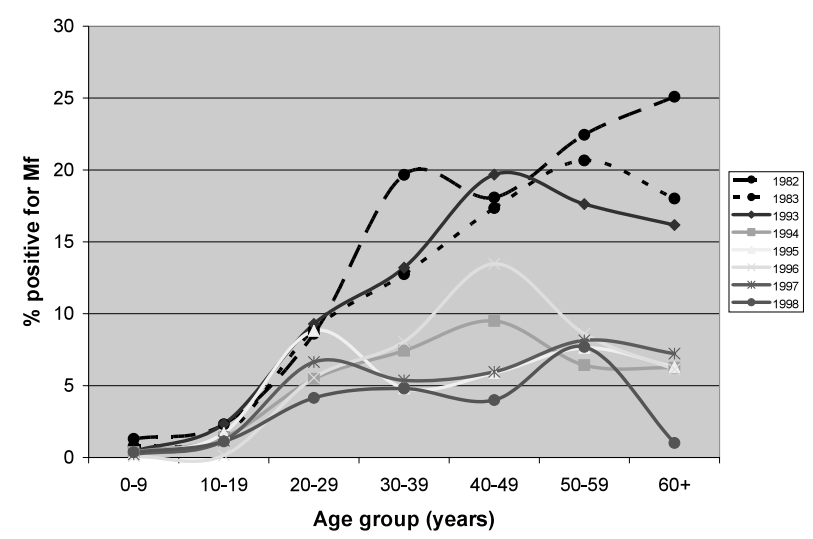


Figure 7: Age-specific prevalence of Mf in Samoa, FEMALES, 1982, 1983 and 1993-1998

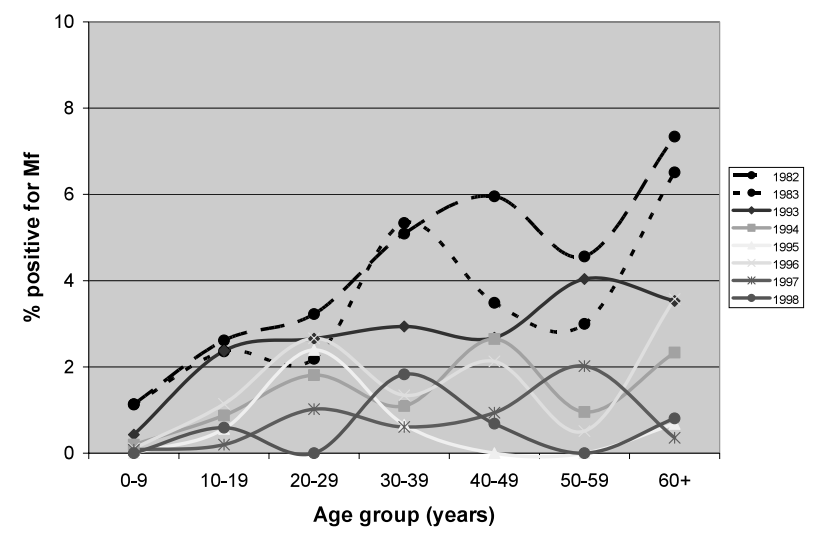

Figure 8: Age-specific prevalence of Mf in Samoa, 1982 to 1983 and 1993 to 1998, both sexes combined.

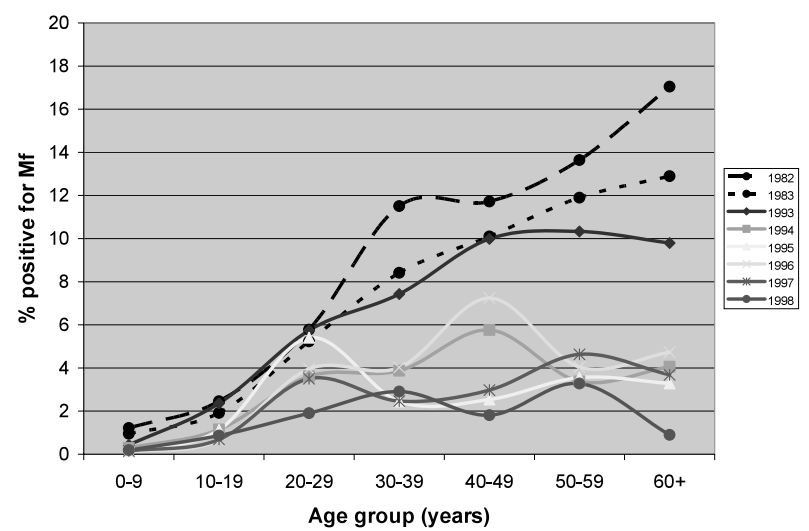

drop in the prevalence of Mf in persons older than 30 years. Prevalence in younger age groups was slower to fall, but by 1998 all except the 50-59 age group were below 5\% prevalence.

In females, the age-specific prevalence curve showed generally lower rates in 1993 than in 1982-3 (Figure 7), and not so marked a change between 1993 and subsequent years. Nevertheless prevalence in all age groups was below $2 \%$ by 1998. Figure 8 presents combined data for both sexes.

The distributions of numbers of Mf $60 \mu \mathrm{l}$ of blood at the start (1993) and end (1998) of the programme are shown in Figure 9. As mentioned above, the geometric mean number of Mf in positive cases declined significantly over the 5year period. Also, between 1993 and 1998, the proportion of high density carriers - people with over $50 \mathrm{Mf}$ per $60 \mu \mathrm{l}$ (1000 Mf/ml) - had declined from over $19.4 \%$ to less than $4 \%\left(\mathrm{P} \chi^{2}=5.61 ; \mathrm{p}=0.018\right)$.
Figure 9: Distribution of Mf numbers in positive cases
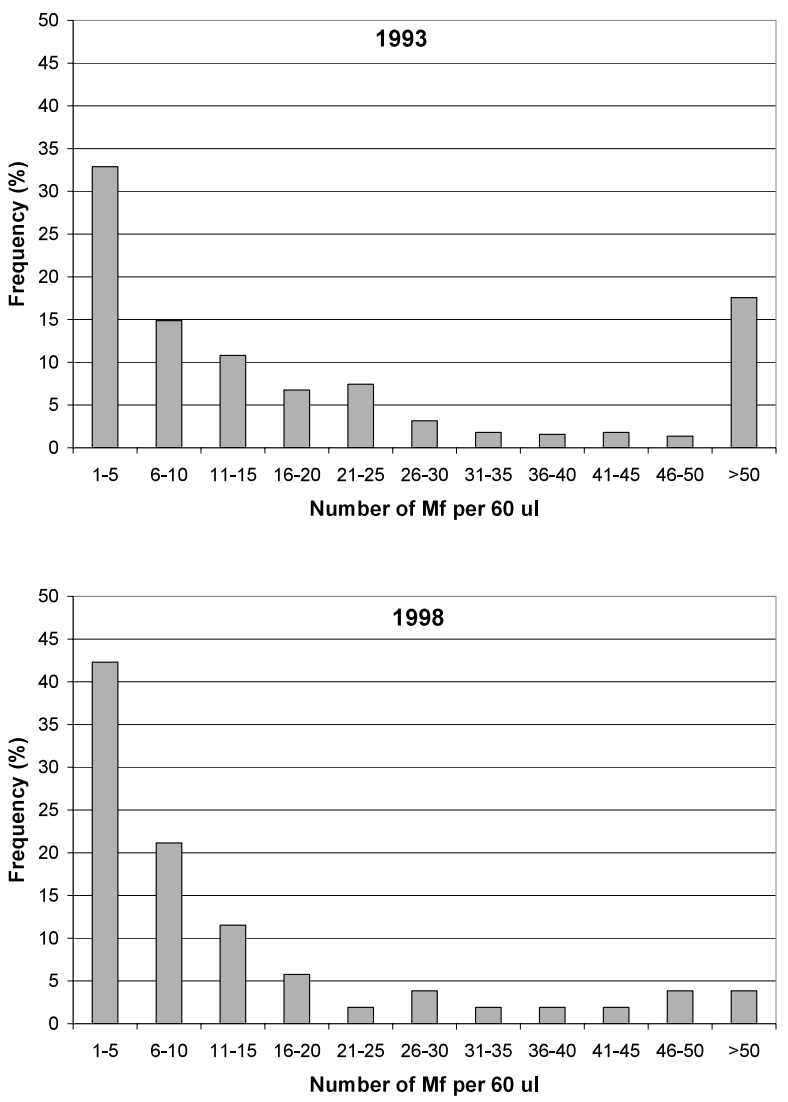

DISCUSSION:

The results provide valuable information on the effects of five years of nationwide MDA on the age- and sex- specific prevalence of $W$. .bancrofti, as well as on the density and frequency distribution of Mf before and after such a program in Samoa. These data may be useful for modeling and predicting the number of years of MDA required for elimination. For example, the age-specific prevalence curves found in Samoa could be used to validate the predictions of the models LYMFASIM and EPIFIL [20].

\section{Effects of $M D A$}

Mass treatment was delivered annually to between 67 and $92 \%$ of the approximately 165,000 people resident in Samoa. Based on large village-based surveys of all age groups conducted before the first MDA in 1993 and one year after the fifth MDA, the prevalence of Mf declined from $4.3 \%$ in 1993 to $1.1 \%$ in 1998 (a reduction of $74 \%$ ).

The antigenaemia prevalence was not tested in 1993 when the ICT test was unavailable. In 1998, the antigenemia prevalence was $4.2 \%$ compared to $1.1 \%$ Mf prevalence by slide test. While Mf prevalence is still regarded as a 'gold 
standard' by the GPELF, these results showed that reliance on the much easier ICT method is a conservative approach to estimating prevalence and demonstrated the ratio between the two estimates.

A significant decline in Mf prevalence occurred on both main islands and in almost all the districts of Samoa, among both males and females. Age- and sex--specific prevalence curves indicated a higher prevalence in males than females in all age groups at the start of the programme, and an increasing infection rate with age. The age-specific prevalence rates of filariasis changed dramatically over the five years of MDA in 1993 to 1998. The largest reduction in infection rate in the MDA years occurred in adult males, but even after five years of MDA, males were still much more likely to be infected than females. This emphasizes the importance of ensuring that a high proportion of adult males are treated every year in MDA campaigns.

This programme demonstrates the successful nationwide implementation of MDA for five years in a large population. It reinforces the successful results obtained using this strategy in other sites in Papua New Guinea [21], Egypt [22] and Zanzibar [23].

The drug distribution in Samoa reached between 67 and $92 \%$ of the registered population each year. However the continued presence of infections in young children suggests that transmission of filariasis was still occurring, and therefore that elimination was not achieved, even by this major effort. The results imply that future elimination efforts may require either more than five years of MDA, an increase in coverage levels to over $80 \%$ in all years, or both.

Previous MDAs in 1965 and 1971 with DEC alone (multiple doses) had reduced the Mf prevalence to $0.2 \%$, after which the disease was able to rebound. However, it is possible that the sampling in the 1970's survey was not fully representative and underestimated the true prevalence. It is also possible that adult worms had not been sufficiently eliminated by the sporadic MDAs. Although the campaign described here lasted for five years, no independent coverage surveys or assessment of systematic non-compliance or compliance rates in different age or sex groups were conducted during this campaign. These are advisable for future programmes, however, because they may identify subgroups that are not being reached.

\section{From Samoa to PacELF}

The current global strategy for filariasis elimination in the Pacific region uses co-administration of DEC and albenda- zole, rather the DEC alone or DEC plus ivermectin as used in the Samoa programme during 1993 to 1997 . Other regions of the world where onchocerciasis is endemic use a combination of ivermectin and albendazole, since DEC can be harmful in persons with onchocerciasis. There is conflicting opinion on whether the DEC/albendazole or ivermectin/albendazole combinations are more effective than DEC or ivermectin alone in killing Mf or adult worms [16, 24], and some evidence suggests that albendazole may actually reduce the effect of DEC on adult worms [25]. On the other hand, albendazole is likely to be beneficial for its effect on other helminth infections.

One year after the conclusion of this control programme in 1998, Samoa became the first nation to start MDA under the auspices of PacELF [26]. The final blood survey in the current series, conducted in 1998, serves as the baseline for monitoring the PacELF programme. Under PacELF, a new drug regimen of DEC/albendazole was used instead of DEC alone or DEC/ivermectin. The PacELF programme also emphasized the use of the Binax ICT test in addition to Mf blood slides, to simplify and accelerate the testing process. Despite these small modifications, the Samoa programme and the extensive knowledge of organizing MDA gained thereby was applicable to the new task. The results of the PacELF MDA programme will be described in future papers.

\section{ACKNOWLEDGEMENTS}

The authors would like to thank to all the health workers, communities and people of Samoa for their brave work and cooperation. We also thank the filariasis control project staff and Japanese Overseas Cooperation Volunteers for their tireless work and contributions. Many thanks go to Dr Eti Enosa, former Director of Health, Samoa and Dr David Parkinson, former WHO Representative, Samoa for their helpful advice and support for the project. Thanks to Dr Patrick Lammie and Dr Michael Deming for comments on the manuscript. We dedicate this paper to the late Dr Lanu Penaia and Dr Leota Tautasi, who were team leaders of the Samoan National Filariasis Control Project during the period of this work.

This study was carried out by the Ministry of Health in collaboration with WHO and the Japan International Cooperation Agency (JICA).WHO provided financial and technical support and JICA provided volunteers. 


\section{REFERENCES}

1 . Samoa Statistical Services Division, Ministry of Finance, Apia, Samoa. Census of Population and Housing 2001. Accessed on Aug1 2006 at http://www.spc.int/prism/Country/ WS/stats/census_survey/census.htm

2 . Ramalingam S. 1968. The epidemiology of filariasis transmission in Samoa and Tonga. Ann Trop Med Parasitol 62: 305-24.

3 . Ichimori K. 2001. Entomology of the filariasis control program in Samoa, Aedes polynesiensis and Ae. samoanus. Med Entomol Zool 52: 11-21.

4 . Samarawickrema WA, Kimura E, Spears GF, Penaia L, Sone F, Paulson GS, Cummings RF. 1987. Distribution of vectors, transmission indices and microfilaria rates of subperiodic Wuchereria bancrofti in relation to village ecotypes in Samoa. Trans Roy Soc Trop Med Hyg 81: 129-35.

5 . Sasa M. Human filariasis. A global survey of epidemiology and control. Japan: The University of Tokyo Press, 1976.

6 . O'Connor FW. 1923. Researches in the Western Pacific being a report on the expedition sent from the London School of Tropical Medicine to the Ellice, Tokelau and Samoan islands in 1921-22. Research memoirs of the London School of Tropical Medicine 4: 57pp.

7 . Buxton PA, Hopkins GHF. 1927. Researches in Polynesia and Melanesia. Parts 1-4. Research memoirs of the London School of Hygiene and Tropical Medicine. 1. 260pp.

8 . Buxton PA, 1928. Researches in Polynesia and Melanesia. Parts 5-7. Research memoirs of the London School of Hygiene and Tropical Medicine. 2, 139pp.

9 . WHO/SPC. Report on the fourth joint WHO/SPC seminar on filariasis and vector control. WPR/FIL/12. Apia, Samoa 1974.

10. Kimura E, Penaia L, Spears GFS. 1985a. Epidemiology of sub-periodic bancroftian filariasis in Samoa 8 years after mass treatment with diethylcarbamazine. Bull WHO 63: 869-880.

11. Kimura E, Spears GFS, Singh KI, Samarawickrema WA, Penaia L, Sone PF, Pelenatu S, Faaiuaso ST, Self LS, Dazo BC. 1992. Long-term efficacy of single-dose mass treatment with diethylcarbamazine against diurnally subperiodic Wuchereria bancrofti: eight years experience in Samoa. Bull WHO 70: 769-776.

12. Suzuki T, Sone F. 1975. Filarial infection in vector mosquitoes after mass drug administration in Western Samoa. Tropical Medicine 16: 147-156.

13. Bryan JH, Southgate BA. 1976. Some observations on fi- lariasis in Western Samoa after mass administration of diethylcarbamazine. Trans Roy Soc Trop Med Hyg 70: 39-48.

14. Kimura E, Penaia L, Samarawickrema WA and Spears GFS 1985b. Low-density microfilaraemia in subperiodic bancroftian filariasis in Samoa. Bull WHO 63: 1089-1096.

15. Gyapong JO, Twum-Danso AYT. 2006. Editorial: Global eliminiation of lymphatic filariasis: fact or fantasy? Trop Med Int Health 11(2): 125-128.

16. Critchley J, Addiss D, Gamble C, Garner P, Gelband H, Ejere H, International Filariasis Review Group. 2005. Cochrane Database Syst Rev. (4).

17 . Ichimori K, Crump A. 2005. Pacific collaboration to eliminate lymphatic filariasis. Trends Parasitol 21: 441-4.

18. Ottesen EA, Ismail MM, Horton J. 1999. The role of albendazole in programmes to eliminate lymphatic filariasis. Parasitology Today 15: 382-386.

19. Ottesen EA. 2000. Editorial: the global programme to eliminate lymphatic filariasis. Trop Med Int Health 5: 5914.

20. Stolk WA, de Vlas SJ, Habbema DF. 2006. Advances and challenges in predicting the impact of lymphatic filariasis elimination programmes by mathematical modeling. $\mathrm{Fi}$ laria J.5: 5.

21. Bockarie MJ, Tisch DJ, Kastens W, Alexander ND, Dimber Z, Bockarie F, Iabm E, Alpers MP, Kazura JW. 2002. Mass treatment to eliminate filariasis in Papua New Guinea. New Engl J Med 347: 1841-8.

22. Ramzy RMR, el Setouhy M, Helmy H, Ahmed ES, Abd Elaziz KM, Farid HA, Shannon WD, Weil GJ. 2006. Effect of yearly mass drug administration with diethylcarbamazine and albendazole on bancroftian filariasis in Egypt: a comprehensive assessment. Lancet: 367: 992-999.

23. Mohammed KA, Molyneux DH, Albonico M, Rio F. 2006. Progress towards eliminiating lymphatic filariasis in Zanzibar: a model programme. Trends Parasitol: 22(7): 340-344.

24 . Gyapong JO, Kumaraswami V, Biswas G, Ottesen E. 2005. Treatment strategies underpinning the Global Programme to Eliminate Lymphatic Filariasis. Expert Opin Pharmacother 6 (20: 179-200.

25 . Dreyer G, Addiss D, Williamson J, Norões J. 2006. Efficacy of co-administered diethylcarbamazine and albendazole against adult Wuchereria bancrofti. Trans Roy Soc Trop Med Hyg 100: 1118-1125.

26. WHO, 2006. The PacELF Way: towards the elimination of lymphatic filariasis from the Pacific. WHO Western Pacific Region, Manila. 